\title{
Investigation of Antimicrobial Effect of Berberine on Ciprofloxacin and Imipenem Resistance Acinetobacter baumannii Isolated from Hamadan Hospitals
}

\author{
Hassan Mahmoudi ${ }^{1,2}$, Nayreh Zare Fahim ${ }^{1}$, Mohammad Yousef Alikhani' ${ }^{2}$, Leili Shokoohizadeh ${ }^{2 *}$
}

1. Students Research Committee, Hamadan University of Medical Sciences, Hamadan, Iran

2. Department of Medical Microbiology, Faculty of Medicine, Hamadan University of Medical Sciences, Hamadan, Iran

Background: Acinetobacter baumannii is one of the causes of nosocomial infections, especially in the intensive care unit. The emergence of multidrug-resistant strains of $A$. baumannii has caused many problems. One of the ways to handle the phenomenon of antibiotic resistance is the use of herbal medicines and their derivatives in place of or in combination with antibiotics. The aim of this study was to investigate the effect of inhibitory effects of berberine as a barberry derivative on clinical isolates of $A$. baumannii, resistant to ciprofloxacin and imipenem in Hamadan hospitals.

Materials \& Methods: In this study, 70 clinical isolates of $A$. baumannii. were identified and diagnosed using conventional microbiology. Resistance of isolates was detected against imipenem and ciprofloxacin by disk diffusion and broth microdilution method. Minimum inhibitory concentration (MIC) of berberine as well as its combined effect with antibiotics were performed using broth microdilution method.

Results: The results of this study showed that more than $90 \%$ of isolates are resistant to ciprofloxacin and imipenem. Imipenem and ciprofloxacin MICs were dtermined from 8 to 28 and 4 to $32 \mu \mathrm{g} / \mathrm{mL}$, respectively. The berberine decreased the imipenem and ciprofloxacin MIC from zero to two fold and zero to one-fold, respectively.

Conclusion: High level resistance to imipenem and ciprofloxacin among A.baumannii isolates is cause of concern. Berberin, in combination with imipenem and ciprofloxacin, reduces MIC to a proper level, which can be used as an effective agent to reduce antibiotic resistance in bacteria.

Keywords: Acinetobacter baumannii, Ciprofloxacin, Imipenem, Berberine

Received: 2019/08/18; $\quad$ Accepted: 2019/12/30; Published Online: 2020/03/14

\begin{tabular}{|c|c|}
\hline Corresponding Information: & $\begin{array}{l}\text { Leili Shokoohizadeh, Department of Medical Microbiology, Faculty of Medicine, Hamadan University of Medical Sciences, } \\
\text { Hamadan, Iran. Email: Leilishokoohizadeh@gmail.com }\end{array}$ \\
\hline (c) (1) (8) & $\begin{array}{l}\text { This is an original open-access article distributed under the terms of the Creative Commons Attribution-noncommercial } 4.0 \text { International License which } \\
\text { edistribution of the material just in noncommercial usages with proper citation. }\end{array}$ \\
\hline
\end{tabular}

Use your device to scan and read the article online

Mahmoudi H, Zare Fahim N, Alikhani M Y, Shokoohizadeh L. Investigation of Antimicrobial Effect of Berberine on Ciprofloxacin and Imipenem Resistance Acinetobacter baumannii Isolated from Hamadan Hospitals. Iran J Med Microbiol. 2020; 14 (1) :44-54

Download citation: BibTeX | RIS | EndNote | Medlars | ProCite | Reference Manager | RefWorks Send citation to: 8 Mendeley 2 Zotero $\overline{\text { RefWorks }}$

\section{Introduction}

Acinetobacter baumannii, is a crucial opportunistic bacterium and common cause of various nosocomial infections such as pneumonia, bacteremia, surgical wound infections, secondary meningitis, and urinary tract infections. One of the problems with $A$. baumannii is the emergence of multidrug resistance (MDR) strains (1). Different mechanisms cause antibiotic resistance of $A$. baumannii, including the production of beta-lactamase enzymes, aminoglycoside-modifying enzymes, and increased expression of efflux pumps. One way to deal with the antibiotic resistance in bacteria is to use medicinal herbs instead of antibiotics. Among the benefits of using medicinal herbs are fewer side effects as well as 
reduced risk of resistance to these compounds. Many studies have investigated the therapeutic and useful effects of medicinal plants and their derivatives on bacteria. Berberine has antibacterial properties against many bacteria, including Escherichia coli, Brucella abortus, Staphylococcus aureus, Pseudomonas aeruginosa, and some fungi. Berberine, as a plant derivative, is a natural alkaloid found in the roots, and rhizomes of Barberry (Berberis vulgaris) and studies have shown that it has therapeutic and antioxidant properties $(2,3)$. Given the importance of treatment for nosocomial infections caused by $A$. baumannii, the availability of Barberry vulgaris and its oral and therapeutic use, this study aimed to evaluate the antibacterial effect of berberine on imipenem and ciprofloxacin- resistant isolates of $A$. baumannii.

\section{Material and Methods \\ Collection of Clinical Isolates}

This research was approved by the Ethics Committee in Research of Hamadan University of Medical Sciences under the specific code of ID IR.UMSHA.REC.1397.238. A total of 70 clinical isolates of A. baumannii were collected from sputum, bronchoalveolar lavage, and endotracheal aspirate specimens of patients admitted to ICU for nine months in 2018, from three educational hospitals of Hamadan University of Medical Sciences. $A$. baumannii isolates were detected using various biochemical and microbiological tests (4).

Antimicrobial Susceptibility of Acinetobacter baumannii Isolates to Berberine

Berberine was prepared as berberine hydrochloride powder (Sigma Co., Germany). Berberine solution was made in a $1 \mathrm{mg} / \mathrm{mL}$ initial solution in dimethyl sulfoxide (DMSO). Ten microliters of this solution were inoculated on Blank paper disks and then placed on a fresh culture of $A$. baumannii comparable to 0.5 McFarland standard, and incubated at $37^{\circ} \mathrm{C}$ for $24 \mathrm{~h}$ and the effect of berberine was investigated as growth inhibition zones around disks (5).

\section{Antimicrobial Susceptibility Testing}

Antimicrobial susceptibility of $A$. baumannii isolates to imipenem $(10 \mu \mathrm{g})$ and ciprofloxacin $(5 \mu \mathrm{g})$ (Mast Co, UK) was determined, by disk diffusion method according to Clinical \& Laboratory Standards Institute (CLSI 2017).

\section{Determination of MICs of Berberine and Imipenem and Ciprofloxacin}

Minimum Inhibitory Concentration (MIC) of imipenem and ciprofloxacin was determined by broth micro-dilution method in 96-well microplates according to standard CLSI protocol (6). Dilution serials of $0.125 \mu \mathrm{g} / \mathrm{mL}$ to $256 \mu \mathrm{g} / \mathrm{mL}$ were prepared from berberine, imipenem, and ciprofloxacin. $100 \mu \mathrm{L}$ of bacterial suspension was added to the wells. The microplates were then incubated at $37^{\circ} \mathrm{C}$ for $24 \mathrm{~h}$. Standard strains of $P$. aeruginosa ATCC 27853 and $E$. coli ATCC 25922 were used as control strains.

\section{Results}

\section{Frequency of $\boldsymbol{A}$. baumannii Isolates}

In this study, 70 (28.1\%) A. baumannii isolates were isolated from 249 positive cultures of respiratory tracts of patients in ICUs. The highest rate of isolation of $A$. baumannii was from endotracheal aspirate samples (57.14\%, $n=40)$ and the lowest rate was from Bronchoalveolar Lavage samples (17.14\%, n=12).

\section{Ciprofloxacin and Imipenem Resistance Rates}

Antibiogram results showed that high level resistance to ciprofloxacin and imipenem; $97.4 \%$ and $94.7 \%$, respectively.

\section{Imipenem and Ciprofloxacin MICs}

Minimum Inhibitory Concentration (MIC) was determined for all clinical isolates (70 isolates) resistant to imipenem and ciprofloxacin by broth microdilution. The MIC values of the strains were committed from 8 to $28 \mu \mathrm{g} / \mathrm{mL}$. Results showed $94.7 \%$ of clinical isolates were resistant to imipenem. MIC values of ciprofloxacinresistant isolates were 4 to $32 \mu \mathrm{g} / \mathrm{mL}$ and $97.4 \%$ of isolates were resistant to ciprofloxacin (Table 1).

\section{Antibacterial Effect of Berberine}

The antibacterial effect of berberine was evaluated by the disk diffusion method, and the mean inhibition zone around the berberine disks showed the antibacterial effect of berberine on A. baumannii isolates.

\section{MIC of Imipenem in Combination with Berberine}

The MIC of Berberine and imipenem alone and in combination with berberine (50\% imipenem and 50\% berberine) was performed on imipenem-resistant strains by broth microdilution method. The combination of berberine and imipenem reduced the MIC levels of imipenem in $(60 \%, n=42)$ of isolates and decreased the MIC between zero to 2-fold (Table 2).

\section{MIC of Ciprofloxacin in Combination with Berberine}

The MIC of Berberine and ciprofloxacin alone and in combination ( $50 \%$ berberine and $50 \%$ ciprofloxacin) were determined by broth microdilution on ciprofloxacin-resistant isolates. The combination of berberine and ciprofloxacin decreased the MIC levels of ciprofloxacin in $(31.4 \%, \mathrm{n}=22)$ A. baumannii isolates and decreased the MIC between zero to 1-fold (Table 3). 
Table 1. Frequency MICs $(\mu \mathrm{g} / \mathrm{mL})$ of imipenem and ciprofloxacin of Acinetobacter baumannii isolates

\begin{tabular}{|c|c|c|c|c|c|c|c|}
\hline MIC $(\mu \mathrm{g} / \mathrm{mL})$ & 2 & 4 & 8 & 16 & 32 & 64 & 128 \\
\hline Imipenem & - & - & $5(7.14 \%)$ & $2(2.8)$ & $35(50)$ & $12(17.1)$ & $16(22.8)$ \\
\hline Ciprofloxacin & - & $31(44.2)$ & $10(14.2)$ & $17(24.2)$ & $12(17.1)$ & - & - \\
\hline
\end{tabular}

Table 2. MIC levels of imipenem in combination with berberine

\begin{tabular}{|c|c|c|c|c|}
\hline $\begin{array}{c}\text { MIC } \\
\text { Imipenem } \\
(\mu \mathrm{g} / \mathrm{mL})\end{array}$ & $\begin{array}{l}\text { MIC Berberine } \\
(\mu \mathrm{g} / \mathrm{mL})\end{array}$ & \begin{tabular}{l}
\multicolumn{1}{c}{ MIC } \\
Imipenem + \\
Berberine
\end{tabular} & $\begin{array}{l}\text { decrease MIC } \\
\text { Imipenem+ } \\
\text { Berberine }\end{array}$ & No(\%) Frequency \\
\hline 8 & 0.5 & 1 & $0-1$ & $5(7.1)$ \\
\hline 16 & 1 & 2 & $0-1$ & $2(2.8)$ \\
\hline 32 & 1 & 4 & $0-1$ & $35(50)$ \\
\hline 64 & 4 & 8 & $0-1$ & $12(17.1)$ \\
\hline 128 & 8 & 16 & $0-2$ & $16(22.8)$ \\
\hline
\end{tabular}

Table 3. MIC levels of ciprofloxacin in combination with berberine

\begin{tabular}{ccccc}
$\begin{array}{c}\text { MIC ciprofloxacin } \\
(\mu \mathrm{g} / \mathrm{mL})\end{array}$ & $\begin{array}{c}\text { MIC Berberine } \\
(\mu \mathrm{g} / \mathrm{mL})\end{array}$ & $\begin{array}{c}\text { MIC Ciprofloxacin }+ \\
\text { Berberine }\end{array}$ & $\begin{array}{c}\text { MIC decrease } \\
\text { Ciprofloxacin+ } \\
\text { Berberine }\end{array}$ & $\begin{array}{c}\text { Frequency } \\
\text { No(\%) }\end{array}$ \\
\hline 4 & 2 & 2 & $0-1$ & $10(14.2)$ \\
8 & 4 & 2 & $0-1$ & $17(24.2)$ \\
16 & 8 & 8 & $0-1$ & $31(44.2)$ \\
32 & 16 & 16 & $0-1$ & $12(17.44)$
\end{tabular}

\section{Discussion}

In the present study, 70 (28.1\%) of cultures of respiratory tract samples were positive for $A$. baumannii. Similarly, Ebrahimi et al. reported that $A$. baumannii isolates were the most common (35\%, $\mathrm{n}=56$ ) bacterial pathogen isolated from respiratory tract samples collected from ICUs in Arak hospitals (10).

In a study by El-Saed et al., 2013 in Saudi Arabia, 457 cultures were collected from the respiratory tract of ICU patients, the most common isolate was $A$. baumannii $(26.5 \%, \mathrm{n}=121)$. These results indicated a high prevalence of $A$. baumannii is in ICUs (9).

In the present study, the results of disk diffusion and broth microdilution tests showed high-level resistance (more than $90 \%$ ) to ciprofloxacin and imipenem antibiotics. In a study conducted in Turkey, resistance to piperacillin, piperacillin-tazobactam, ciprofloxacin and ceftazidime were $100 \%, 92.4 \%, 83.3 \%$, and $74.2 \%$, respectively, and high levels of resistance to other antibiotics were detected (15). Consistent with our study in the study of Vazirizadeh et al., the rates of antibiotic resistance to ciprofloxacin, and imipenem were $96 \%$ and $98 \%$, respectively, in Isfahan hospitals (16).

In our study, berberine was found to be active on $A$. baumannii and inhibition zone was observed around the disks containing berberine and berberine in combination with imipenem and ciprofloxacin reduced the MIC of these antibiotics. Consistent with the present study, in 2017, Aghayan et al. showed that palmatine and berberine had decreased the MIC and $\mathrm{MBC}$ levels of ciprofloxacin in ciprofloxacin-resistant 
isolates of $P$. aeruginosa and there was no significant difference between the effect of palmatine and berberine (17).

In a study by Musumeci et al. from Italy, the bactericidal effect of the methanolic extract of Barberry (Berberis aetnensis) on $S$. aureus was investigated. The results showed that MIC decreased considerably when using the combination of extract and antibiotic compared to ciprofloxacin alone and the plant extract. Barberry and ciprofloxacin antibiotics showed a synergistic effect (18).

In 2014, Wojtyczka et al. in Poland reported the antimicrobial effect as well as the synergistic effect of berberine and some of antibiotics on coagulasenegative Staphylococci including Staphylococcus epidermidis, Staphylococcus capitis, Staphylococcus gallinarum, Staphylococcus hominis and Staphylococcus intermedius (19).

The results of this study and other studies showed that berberine has antibacterial properties and can be used as a cheap and available source for therapeutic use in some bacterial infections. In other words, berberine can be considered as a suitable alternative or supplement to synthetic antibiotics against $A$. baumannii isolates.

\section{Conclusion}

The findings of this study showed the antibacterial effects of berberine, and that it can increase the effectiveness of antibiotics against imipenem and ciprofloxacin-resistant isolates of $A$. baumannii. Berberine can be used in the future by optimizing the methods for the treatment of infectious diseases caused by $A$. baumannii.

\section{Acknowledgment}

This article is taken from a student research project No. 9704192213 approved by the Student Research Committee of Hamadan University of Medical Sciences. The authors of this article would like to extend their gratitude to Hamadan University of Medical Sciences for their financial support as well as to the staff of intensive care units in Besat, Sina and, Shahid Beheshti hospitals in Hamadan.

\section{Conflict of Interest}

Authors declared no conflict of interests. 


$$
\begin{aligned}
& \text { مجله ميكروبشناسى يزشكى ايران } \\
& \text { سال F| ـ شماره ا ـ بهمن و اسفند 94ج| }
\end{aligned}
$$

\title{
بررسى تاثير ضد باكتريايى بربرين بر ايزولههاى اسينتوباكتر بومانى مقاوم به

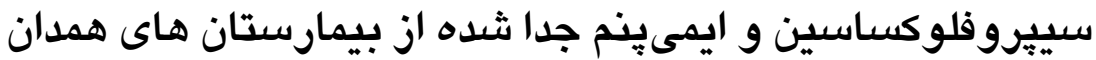

\author{
حسن محمودى'، نيره زارع فهيم'، محمديوسف عليخانى ' ليلى شكوهى زاده r"
}

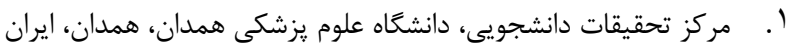

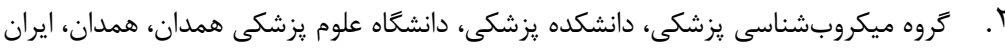

\section{جكيله}

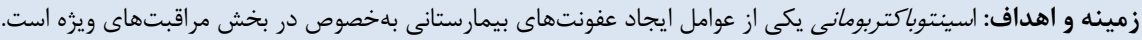

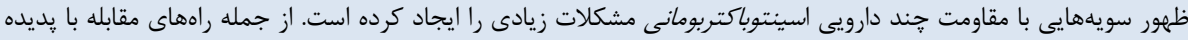

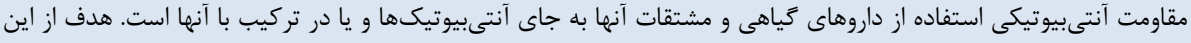

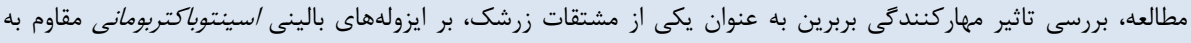
سييروفلوكساسين و ايمى ينم است.

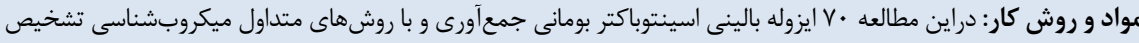

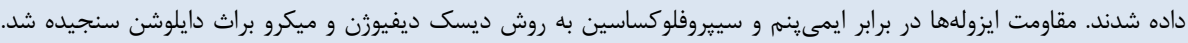

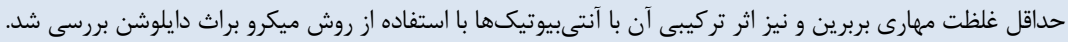
يافته ها: نتايج حاصل از اين مطالعه نشان داد بيش از • 9 درصد ايزولهها نسبت به سييروفلوكساسين و ايمىينم مقاوم بودند.

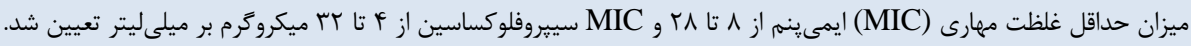

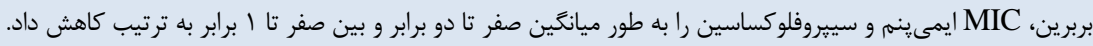
نتيجه كيرى: مقاومت سطح بالا به ايمى ينم و سييروفلوكساسين در ميان ايزوله هاى /سينتوباكتر بومانى موجب نكرانى است.

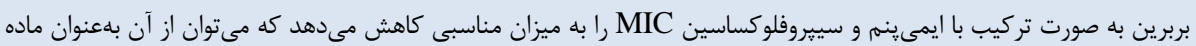
موثرى جهت كاهش مقاومت آنتىبيوتيكى در باكترى ونها استفاده كرد. كليد وازهها: اسينتوباكتر بومانى، سييروفلوكساسين، ايمىينم، بربرين
اطلاعات مقاله

تاريخجهُ مقاله

دريافت:

يذيرش:9+|+1/1

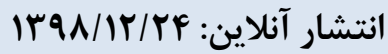

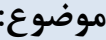

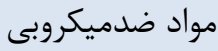

نويسندهُ مسئول:

ليلى شكوهى زاده، كروه ميكروبشناسى دئى

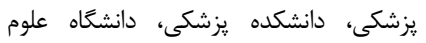
يزشكى همدان، ايران ايميل:

leilishokoohizadeh@gmail.com

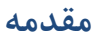

مقاومت آنتىبيوتيكى استفاده از داروهاى گياهى به جاى آنتى بيوتيكها است. از جمله مزاياى استفاده از داروهاى گياهى كمتر بودن عوارض جانبى و همجنين كاهش احتمال بروز مقاومت به اين تركيبات است. مطالعات زيادى اثرات درمانى و مؤثر كياهان دارويى و مشتقات آنها را بر باكترىها بررسى كردهاند. بربرين داراى خاصيت ضدباكتريايى عليه بسيارى از باكترىها از جمله

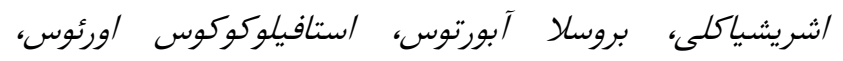
سودوموناس آئروزينوزا و برخى از قارجها است. بربرين بهعنوان يك مشتق گياهى، به صورت يك آلكالوئيد طبيعى است كه در ريشه و
اسينتوباكتر بومانى بهعنوان يك باكترى ياتوزن فرصت طلب مهرم، عامل ايجاد عفونتهاى بيمارستانى مختلفى از قبيل ينومونى،

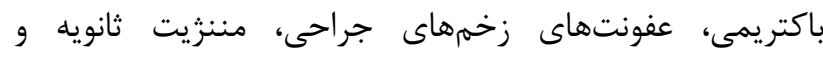
عفونتهاى مجارى ادرارى است. يكى از مشكلات موجود در مورد اسينتو باكتر ظهور سويههايى با مقاومت جند دارويى (MDR) است (1). مكانيسمهاى مختلفى موجب مقاومت آنتىبيوتيكى اسينتوباكتر بومانى مىشود كه شامل توليدآنزيمهاى بتالاكتاماز،

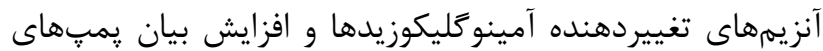
تراوشى (افلاكس ڤيمبها) است. يكى از راههاى مقابله با يديده 
همراه يك ديسك ديكر ( بهعنوان شاهد كه فقط حاوى DMSO است) بر روى كشت تازه/سيتتوباكتر بومانى با غلظت نيم مك فارلند قرار داده شد و يس از يك شبانهروز انكوباسيون تاثير ديسكهاى دئي

حاوى بربرين باصورت تشكيل هاله عدم رشد بررسى شد (ه).

\section{تعيين ميزان حساسيت به آنتىبيوتيكهاى ايمىينم و سييروفلوكساسين}

ميزان حساسيت ضد ميكروبى و يا مقاومت ايزولههاى

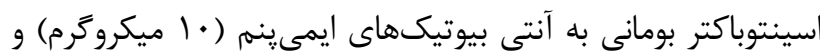

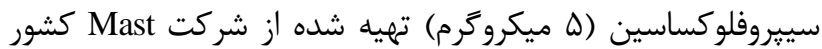
انغَلستان به روش ديسك ديفيوزن براساس ڤيروتكل استاندارد Clinical \& Laboratory Standards Institute (CLSI 2017)

شد (9)

\section{تعيين ميزان MIC بربرين و آنتىبيوتيك هاى ايمىينم و سيبروفلوكساسين}

حداقل غلظت مهارى (MIC) به روش ميكرو براث دايلوشن CLSI; 2017 درميكرويليت وه خانهاى براساس :روتكل استاندارد براى همأ ايزولههاى /سينتوباكتر بومانى تعيين شد (9). بدين

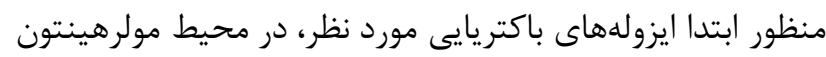

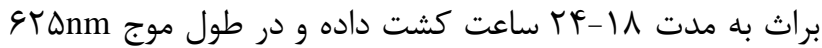
سوسيانسيونى با جذب ^ • • • تا | تهيه شد، سيس • إميكروليتر از سوسيانسيون باكتريايى به •99 ميكروليتر محيط مولر هينتون

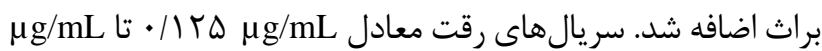

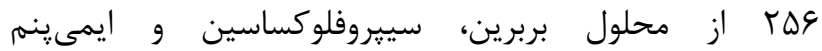
درميكرويليتهاى 99 خانهاى تهيه شده و • •ا ميكروليتر از

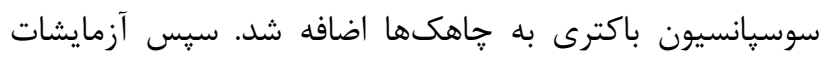
مشابه براى كنترل مثبت (محيط كشت حاوى باكترى و بدون آنتىبيوتيك) و كنترل منفى (محيط كشت بدون باكترى) نيز انجام

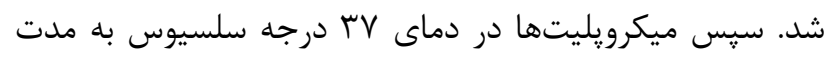

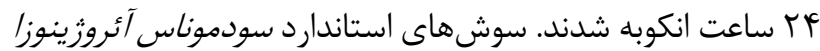
ATCC 27853 كنترل مورد استفاده قرارگرفتند.

\section{تجزيهوتحليل آمارى}

براى تجزياهوتحليل دادهها از نرمافزار SPSS نسخه شماره 19 استفاده شد. و با استفاده از (SPSS Inc., Chicago, Ill., USA) روش كاى اسكوئر، نتايج تجزيهوتحليل شدند. سطح معنادارى

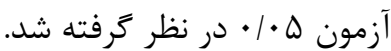

ريزومهاى زياه زرشك (بربريس ولتاريس) يافت مىشود و مطالعات نشان داده كه داراى خواص درمانى و آنتى اكسيدانى است (Y، (Y). مطالعات نشان داده از جمله ويزگى هاى مهرم اين ماده خاصيت آبخريزى اجزاء تشكيل دهنده آن است كه موجب نفوذ

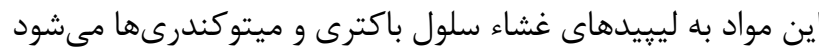
و در نتيجه سبب اختلال در ساختمان آنها و ايجاد نفوذيذيرى موى بيشتر مى گردد كه اين مساله موجب خروج و نشت يونها و ديخر محتويات سلولى به خارج از سلول مىشود. با توجه به اهيمت

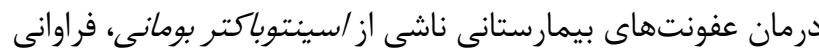

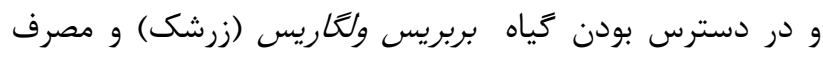
خوراكى و درمانى آن و محدود بودن مطالعات در زمينه اثر بربرين بر اين باكترى، هدف از اين مطالعه بررسى اثر ضد باكتريايى بربرين بهعنوان يكى از مشتقات گياه بربريس ولعاريس بر ايزولههاى مقاوم

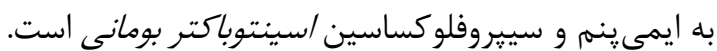

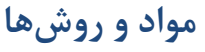 جمع آورى ايزولههاى بالينى} در مطالعه حاضر كه از نوع تجربى است در مجموع • ايزوله بالينى اسينتوباكتربومانى از نمونههاى خلط، برونكوآلولار، لاواز و

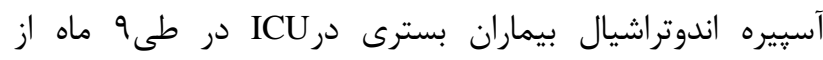

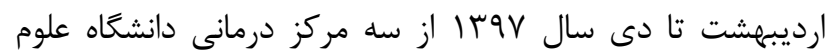
يزشكى همدان (بيمارستان بعثت ، بيمارستان شهيد بهشتى و

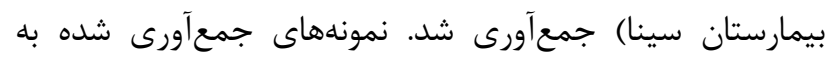

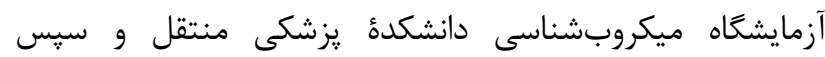
ايزولههاى اسينتوباكتربومانى با استفاده از تستهاى بيوشيميايى مانى مختلف نظير رشد بر روى محيط مك كانكى آكار، رشد در دماى بf

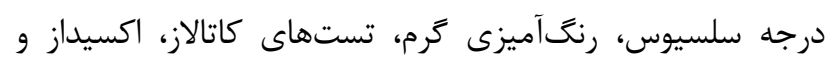
اورهآز، سيمون سيترات، (OF)، Kliglers Iron Agar (KIA) Sulfide Indole Motility (SIM) „Oxidative/fermentative تشخيص داده شدند (F). (F)

\section{تعيين حساسيت ضد ميكروبى ايزولههاى اسينتوباكتربومانى در برابر بربرين}

بربرين بهصورت يودر بربرين هيدروكلرايد (شركت سيخما،

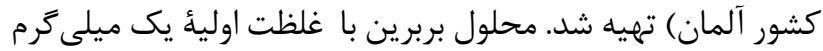

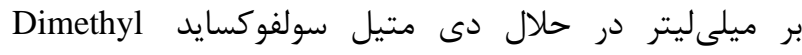
sulfoxide (DMSO) ديسكهاى كاغذى بلانك تلقيح شده و سيس اين ديسكها به 


\section{اثر ضدباكتريايى بربرين}

ميزان حساسيت ايزولههاى بالينى /سينتوباكتر بومانى نسبت

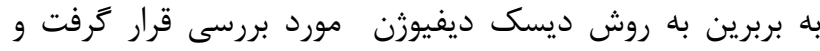

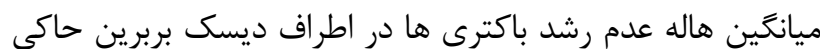
از اثر ضد باكترياى بربرين بود.

\section{ميزان MIC ايمى ينم به صورت تركيب با بربرين}

حداقل غلظت مهارى (MIC) بربرين و ايمى ينم، بهتنهايى و

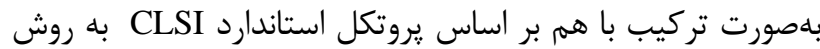

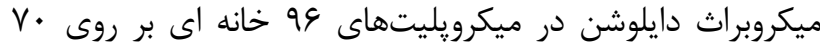
ايزوله مقاوم به ايمىينم انجام شد. سريكالهاى رقت معادل بg/mL

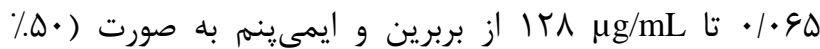
ايمى ينهم و •D. بربرين) در ميكرويليتهاى و9 خانهاى تهيه شد.

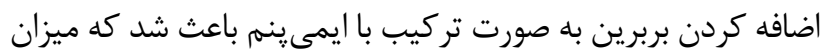
MIC MIC بين صفر تا Y برابر مشاهده شد (جدول Y ).

\section{ميزان MIC سييروفلوكساسين به صورت تركيب با بربرين}

حداقل غلظت مهارى (MIC) بربرين و سييروفلوكساسين، CLSI بهتنهايى و بلهورت تركيب با هم بر اساس يروتكل استاندارد بردين به روش ميكرودايلوشن براث در ميكرويليتهاى צو خانهاى بر روى V.

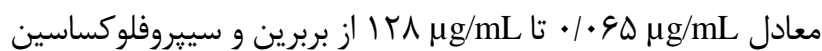

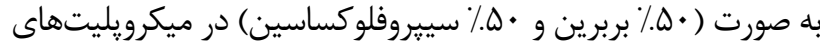

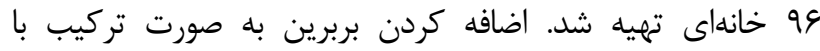

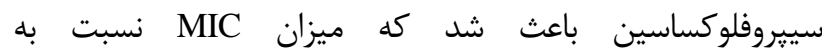

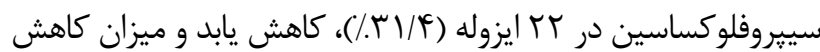
MIC

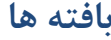

\section{فراوانى ايزولههاى بالينى /سينتوباكتربومانى}

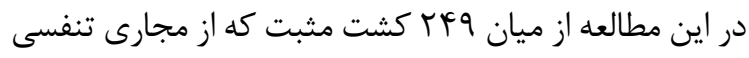
بيماران بسترى در بخش ICU بيمارستانهاى آموزشى شهر همدان

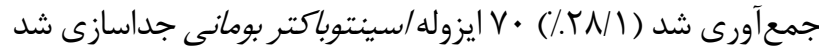

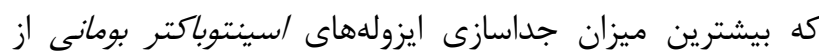

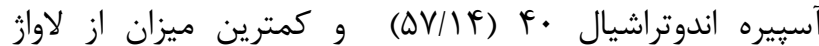

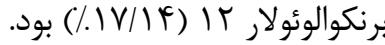

ميزان مقاومت آنتى بيوتيكى ايزولههاى اسينتو باكتر بومانى به سيبروفلوكساسين و ايمىينم نتايج آنتى بيوكرام به روش ديسك ديفيورن بر روى • V ايزوله

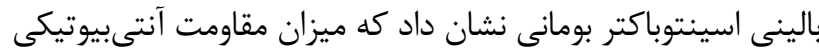

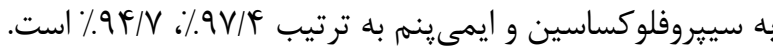
تعيين ميزان MIC ايمىينم و سييروفلوكساسين ايزولههاى اسينتوباكتر بومانى

ح حاقل غلظت مهارى (MIC) براى همه ايزولههاى بالينى (MIC) ايزوله) در ايزولههاى مقاوم به ايمى ينهم و سييروفلوكساسين به روش الهات

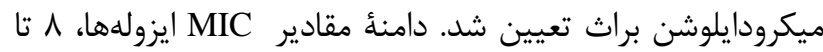

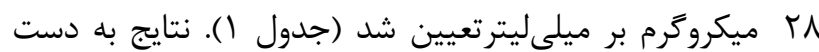

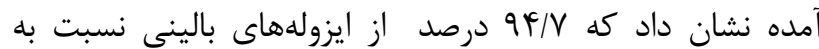
ايمى ينمم مقاوم بودند. نتايج MIC نسبت به سييروفلوكساسين نشان

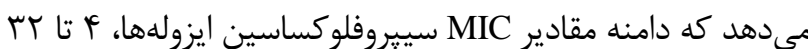

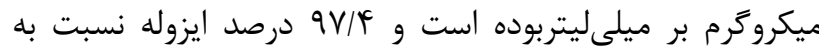
سييروفلوكساسين مقاوم بودند (جدول ().

جدول ا. توزيع فراوانى MIC ( 1 ايمى ينهم وسييروفلوكساسين ايزولهاى اسينتوباكتر بومانى بر اساس تعداد و درصد

\begin{tabular}{|c|c|c|c|c|c|c|c|}
\hline$r$ & f & $\Lambda$ & 19 & re & gf & ITA & آنتىبيوتيك \\
\hline- & - & $\Delta(V / / Y)$ & $r(Y / \Lambda)$ & $r \Delta(\Delta \cdot)$ & $I T(I V / I)$ & $1 \varepsilon(Y Y / \Lambda)$ & ايمىينم \\
\hline- & $M(F \in / T)$ & $1 \cdot(I F / T)$ & $I V(Y Y / T)$ & $I T(I V / I)$ & - & - & سييروفلوكساسين \\
\hline
\end{tabular}




\begin{tabular}{|c|c|c|c|c|}
\hline 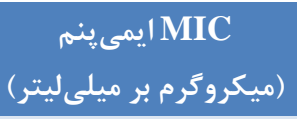 & بربر بن & 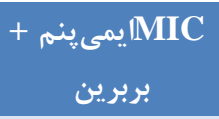 & كاهش MIC ايمى ينه + بربرين & فراوانى (درصد) \\
\hline$\wedge$ & $\cdot 10$ & 1 & $1-\cdot$ & $\Delta(V / \mid Q)$ \\
\hline 19 & 1 & r & $1-\cdot$ & $r(T / \wedge \Delta)$ \\
\hline rr & 1 & r & $1-\cdot$ & $r \Delta(\Delta \cdot)$ \\
\hline$g F$ & r & $\wedge$ & $1-\cdot$ & $I T(|V /| \Delta)$ \\
\hline IrA & $\wedge$ & 19 & $r_{-} \cdot$ & $19(Y r / \wedge Q)$ \\
\hline
\end{tabular}

جدول r. ميزان MIC سييروفلوكساسين به صورت تركيب با بربرين

\begin{tabular}{|c|c|c|c|c|}
\hline 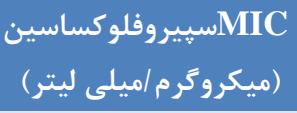 & MIC & بربيروفلو كساسين + & 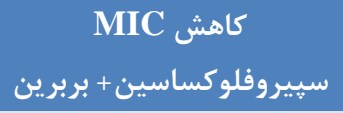 & فراوانى (درصد) \\
\hline$p$ & f & r & $1-\cdot$ & $1 \cdot(\mid f / T)$ \\
\hline$\wedge$ & f & f & $1-\cdot$ & $I V(Y F / Y)$ \\
\hline 18 & $\wedge$ & $\wedge$ & $1-\cdot$ & $r(F F / T)$ \\
\hline Tr & 19 & 19 & $1-\cdot$ & $I T(I V / F F)$ \\
\hline
\end{tabular}

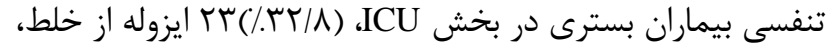

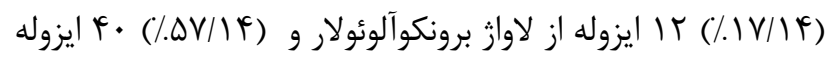

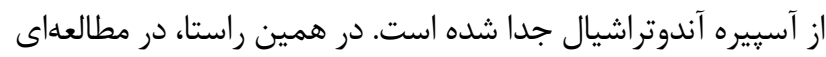

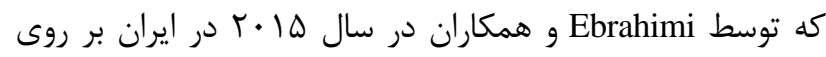
| | | كشت مثبت كه از مجارى تنفسى بيماران بسترى در بخش

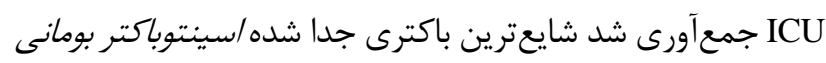
با وها (هَ.) ايزوله گزارش شده است (•(1). در مطالعهاى كه توسط

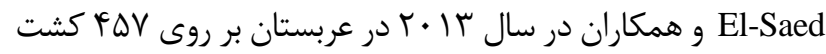
مثبت كه از مجارى تنفسى بيماران بسترى در بخش

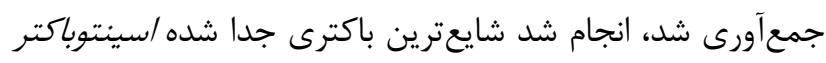

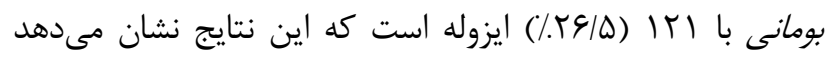

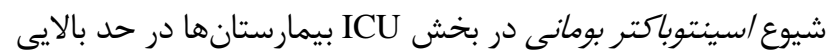
است (II). در مطالعة Safari و همكاران در سال ع أ • ب در همدان • . ايزوله /سينتو باكتر بومانى جدا شده از مجارى تنفسى بيماران بسترى در بخش ICU جمع آورى شده بود كه شايعترين مكان جداسازى ايزولهها از آسييره آندوتراشيال VY٪ بوده است (Y).

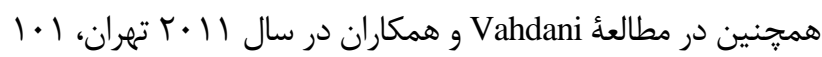
ايزوله/سينتوباكتر بومانى جدا شده از مجارى تنفسى بيماران بسترى

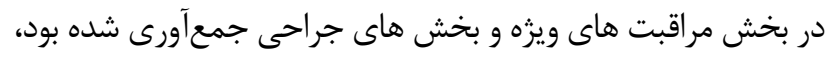

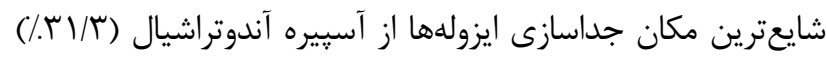

اسينتوباكتر بومانى بهعنوان يكى از مهمترين باكترىهاى

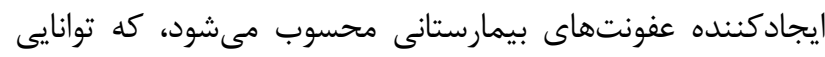
ايجاد طيف وسيعى از عفونتهاى بيمارستانى نظير باكتريمى، عفونت

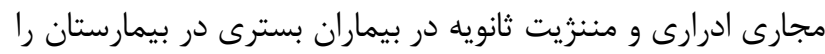
دارد (V)، ولى اهميت زياد اين باكترى در ايجاد ينومونى بيمارستانى

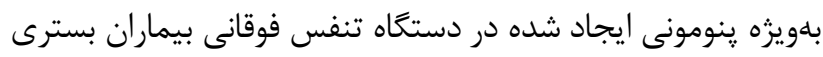

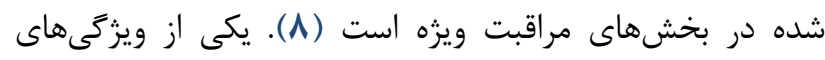
منحصر به فرد اين باكترى توانايى مقاومت ذاتى و اكتسابى نسبت به به طيف گستردهاى از آنتىبيوتيكهاى مورد استفاده در محيط مريط بيمارستان است، كه افزايش روز افزون مقاومت داروئى نسبت به به آنتىبيوتيكهاى مختلف در يى داشته است. درحال حاضر شاهد حضور سويههايى از اين اركانيسم با الگوى مقاومت داروئى جند

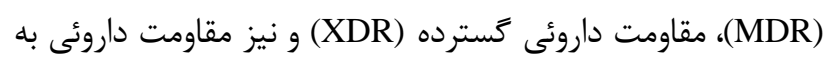
همؤ داروها (PDR) را شاهد هستيم. اين امر در حال حاض حاضر نيز مشكلات فراوانى را براى يزشكان در درمان بيماران آلوده به اين ار Fانيسم هاى مقاوم ايجاد كرده است (9). در مطالعهُ حاضر، از ميان

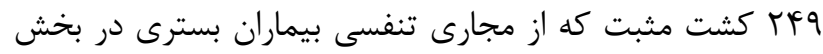
جمعآورى شد (ICU جداسازى شد. كه با مطالعات انجام شده قبلى مشابه بود. در اين

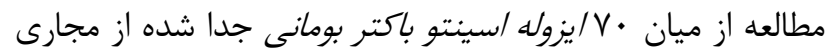


مقاومت آنتىبيوتيكى ايزولهها به روش ديسك ديفيوزن و همجنين

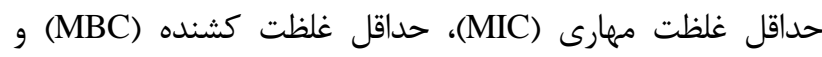

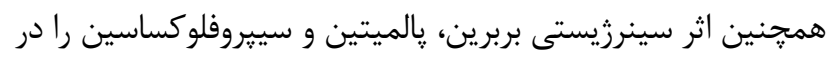

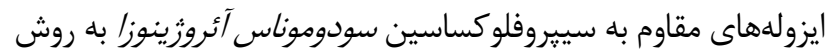
ميكروبراث دايلوشن بررسى كردند. نتايج نشان داد كه سير يالميتين و

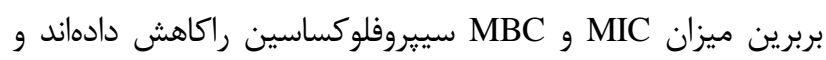

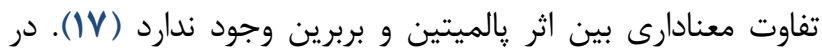
مطالعهاى كه در سال r . P. M توسط Musumeci و همكاران در ايتاليا

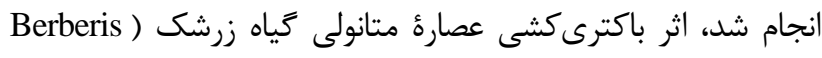
(aetnensis

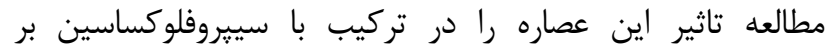
استافيلوكوكوس اورئوس به روش ميكرو براث دايلوشن بررسى كردند

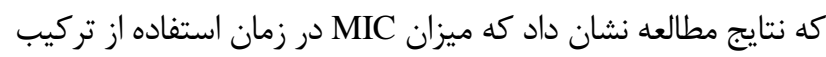

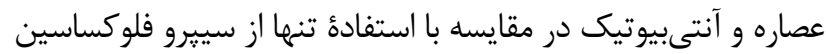
بلمطور جشمخيرى كاهش داشته است و عصارة كياه زرشك و

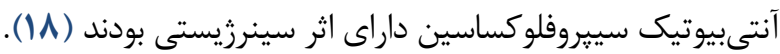

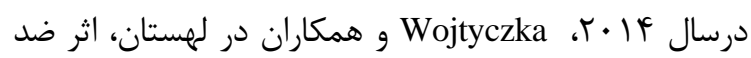
ميكروبى و همجنين اثر سينرزيستى بربرين و تعدادى از

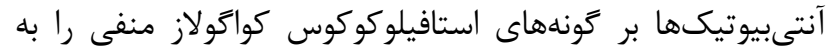

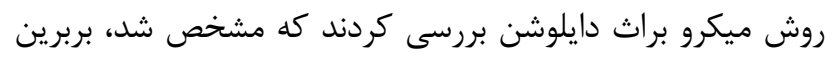

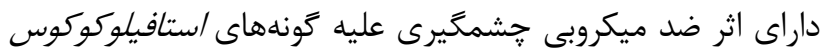
هموليتيكوس، استافيلوكوكوس /بيدرميديس، كإِيتيس، كاليناريوم،

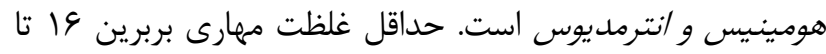

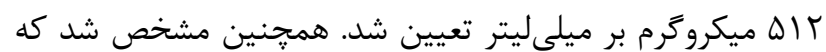

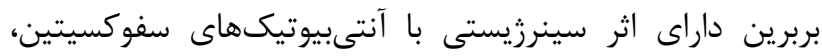

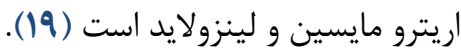

هم جنين در بررسىهاى آنتى باكتريال بربرين، كمترين

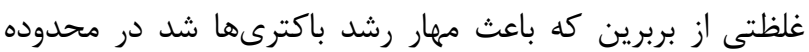

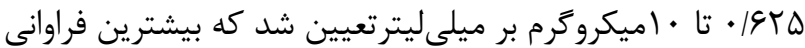
در غلظت MIC در اين مطالعه محدوديتهايى نيز وجود داشت از جمله اينكه اسانس و عصاره كياه مورد مطالعه نيز بايستى بررسى مى ديد و و

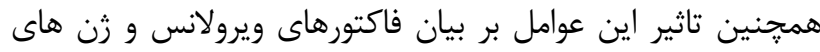

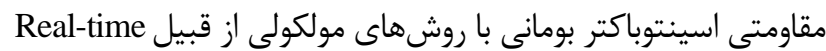
مورد ارزيابى قرار مى كرفت، كه با توجه به محدوديتهاى شديد مالى طرحهاى دانشجويى امكان دستيابى به جنين اهدافى فراهم نشد.
بود (سا). شيوع ايزولههاى مقاوم /سينتوباكتر بومانى در بيشتر نقاط دنيا رو به افزايش است و اين مطالعات نشان مىدهد، مقاومت نه تنها

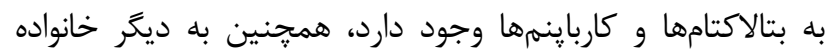
دارويى شامل آمينوخليكوزيدها و فلوروكينولونها نيز گسترش ييدا كرده است كه موجب محدوديت درمانى در اين ايزولهها شده است

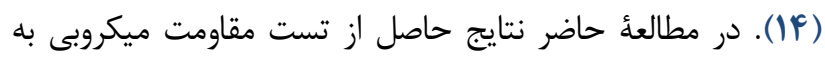
روش ديسك ديفيوزن و ميكرودايلوشن براث نشان مىدهد كه

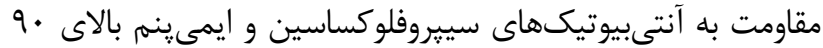
درصد است. بر همين اساس، در مطالعهاى در تركيه، در ايزولههاى

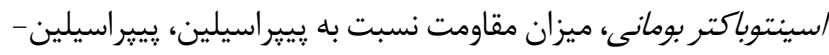

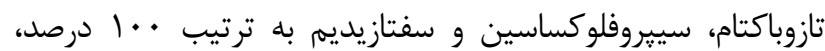
T بالايى نسبت به ساير آنتى بيوتيك ها داشتهاند (ها). همسو با مطالعة ما در مطالعه Vazirizadeh و همكاران در بيمارستان هاى شهر

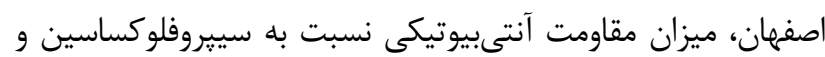

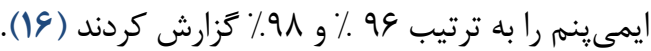
باتوجه به اهميت بالينى باكترى/سينتو باكتر بومانى و محدود

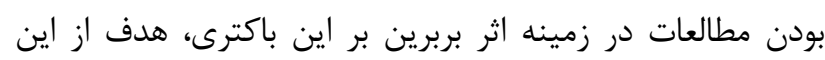

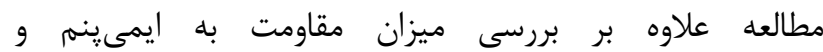
سييروفلوكساسين در ايزولههاى اسينتوباكتر بومانى جدا شده از ازئ

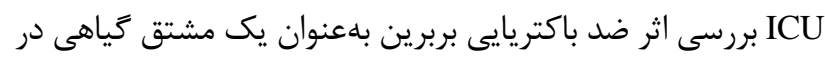

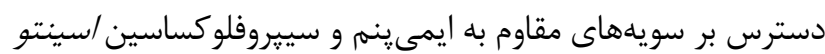
باكتر بومانى بود. در مطالعئ حاضر مشخص شد كه بربرين بر باكترى

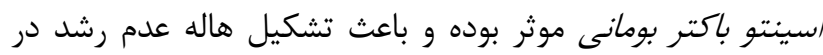
اطراف ديسك حاوى بربرين مىشود و از طرفى بربرين در تركيب با بوان ايمى ينم و سييروفلوكساسين باعث كاهش ميزان MIC اين آنتىبيوتيكها شد. نتايج حاصل از اين مطالعه نشان مىدهد كه بهد

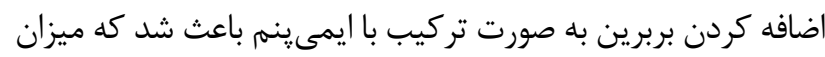

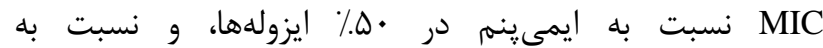
سيِيروفلوكساسين در حدود هأ درصد ايزولهها كاهش يابد و ميزان

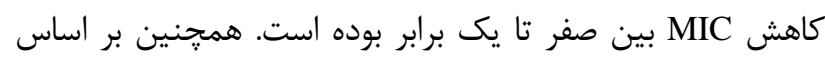
نتايج حاصل از اين مطالعه، بربرين به صورت تركيب بائ با ايمىينه

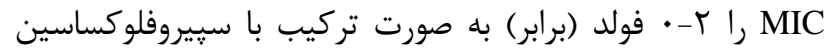
را IIC MIC

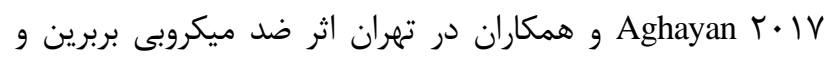

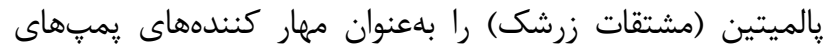

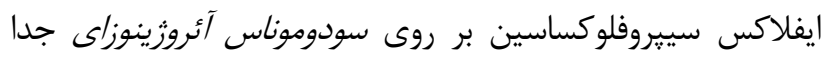

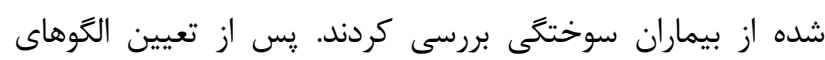




$$
\begin{aligned}
& \text { روشهاى استفاده از بربرين براى درمان بيمارىهاى ناشى از } \\
& \text { عفونتهاى ناشى از سويههاى /سينتوباكتر بومانى استفاده نمود. } \\
& \text { سياسگَزارى } \\
& \text { اين مقاله برگرفته از يك طرح تحقيقاتى دانشجويى به شماره }
\end{aligned}
$$

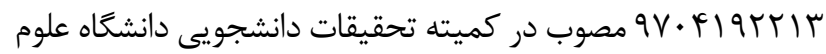

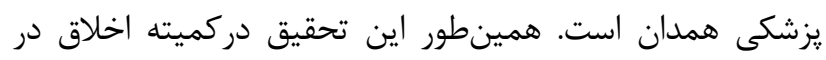

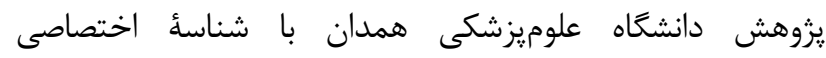

$$
\begin{aligned}
& \text { IR.UMSHA.REC.1397.238 تصويب شد. نويسندكان اين مقاله } \\
& \text { از معاونت يزوهشى دانشكاه علوم يزشكى همدان بدادليل حمايت }
\end{aligned}
$$

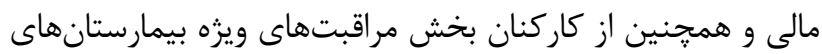

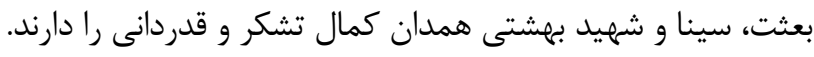

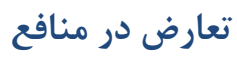

در انجام مطالعهُ حاضر، نويسندَان هيجَّونه تضاد منافعى

نداشتهاند.

\section{Referance}

1. Navidinia M. The clinical importance of emerging ESKAPE pathogens in nosocomial infections. Archives of Advanced in Bioscience. 2016;7(3):43-57.

2. Gao WW, Gopala L, Bheemanaboina RRY, Zhang GB, Li S, Zhou CH. Discovery of 2-aminothiazolyl berberine derivatives as effectively antibacterial agents toward clinically drug-resistant Gram-negative Acinetobacter baumanii. European journal of medicinal chemistry. 2018;146:15-37. [DOI:10.1016/j.ejmech.2018.01.038] [PMID]

3. Jung J, Park W. Acinetobacter species as model microorganisms in environmental microbiology: current state and perspectives. Applied microbiology and biotechnology.

2015;99(6):2533-48. [DOI:10.1007/s00253-015-6439-y] [PMID]

4. Winn WC, Allen SD, Janda WM, Koneman EW, Procop GW, Schreckenberger PC, et al. Taxonomy, biochemical characteristics and clinical significance of medically important nonfermenters. In: Darcy $\mathrm{P}$, Peterson N, editors. Koneman's Colour Atlas and Textbook of Diagnostic Microbiology. 6th ed. Philadelphia: Lippincott Williams and Wilkins; 2006. pp. 353-5

5. Makvandi M, Shokoohizadeh L. Antibacterial and Drug Synergistic Activities of Mentha longifolia Essential Oil Against Shigella flexneri and Shigella sonnei. Int J Enteric Pathog. 2017;5(3):92-5. [DOI:10.15171/ijep.2017.21]

$$
\begin{aligned}
& \text { نتايج مطالعات مختلف كه با استفاده از ماده بربرين و } \\
& \text { آنتىبيوتيكهاى مخلتف بر روى باكترىهاى متفاوتى انجام شد برد } \\
& \text { نشان داد كه بربرين داراى خاصيت ضد باكتريايى است و مى بتواند } \\
& \text { بلهعنوان يك منبع ارزان و در دسترس براى استفاده درمانى در }
\end{aligned}
$$

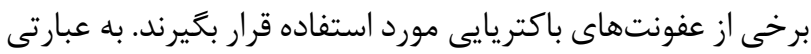

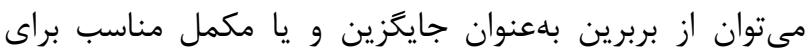

$$
\begin{aligned}
& \text { آنتىبيوتيكهاى صناعى جهت مقابله با ايزولههاى مورد آزمايش } \\
& \text { در نظر كرفت. البته، در اين خصوص مطالعات بيشترى نياز است } \\
& \text { تا بتوان اثرات ضد ميكروبى بربرين را دقيقتر بر بر برسى كرد. } \\
& \text { نتيجه } \\
& \text { يافتههاى اين مطالعه مشخص نمود كه بربرين داراى اثرات }
\end{aligned}
$$

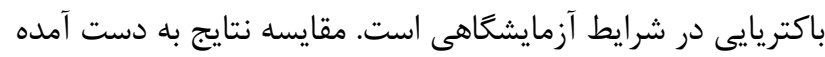

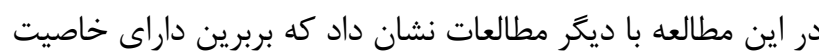

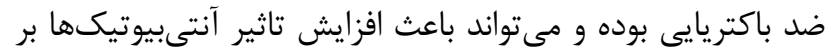

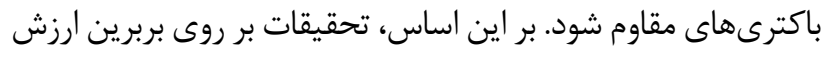

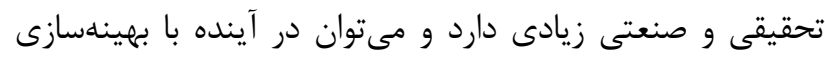

6. Clinical and Laboratory Standards Institute [CLSI] CaL, Standards Institute. : Twenty seventh Informational Supplement M100eS27 CLSI C, Wayne P. Performance Standards for Antimicrobial Susceptibility

7. Oddo A, Thomsen TT, Kjelstrup S, Gorey C, Franzyk $\mathrm{H}$, Frimodt-Møller $\mathrm{N}$, et al. An amphipathic undecapeptide with all $\mathrm{d}$-amino acids shows promising activity against colistin-resistant strains of acinetobacter baumannii and a dual mode of action. 2016;60(1):5929. [DOI:10.1128/AAC.01966-15] [PMID] [PMCID]

8. Cherkaoui A, Emonet S, Renzi G, Schrenzel J. Characteristics of multidrug-resistant Acinetobacter baumannii strains isolated in Geneva during colonization or infection. Annals of clinical microbiology and antimicrobials. 2015;14:42-. [DOI:10.1186/s12941-015-0103-3] [PMID] [PMCID]

9. El-Saed A, Balkhy HH, Al-Dorzi HM, Khan R, Rishu $\mathrm{AH}$, Arabi YM. Acinetobacter is the most common pathogen associated with late-onset and recurrent ventilator-associated pneumonia in an adult intensive care unit in Saudi Arabia. International journal of infectious diseases : IJID : official publication of the International Society for Infectious Diseases. 2013;17(9):e696-701. [DOI:10.1016/j.ijid.2013.02.004] [PMID]

10. Ebrahimi M, Khansari-nejad B, Ghaznavi-Rad E. High Frequency of Ventilator Associated Pneumonia Nosocomial Co-Infection Causedby Methicillin 
Resistant Staphylococcusaureus and Carbapenem Resistant Acinetobacter baumannii in Intensive Care Unit. JOURNAL OF IRANIAN CLINICAL RESEARCH. 2015;1:67-71.

11. El-Saed A, Balkhy HH, Al-Dorzi HM, Khan R, Rishu $\mathrm{AH}$, Arabi YMJIJoID. Acinetobacter is the most common pathogen associated with late-onset and recurrent ventilator-associated pneumonia in an adult intensive care unit in Saudi Arabia. 2013;17(9):e696e701. [DOI:10.1016/j.ijid.2013.02.004] [PMID]

12. Safari M, Mozaffari Nejad AS, Bahador A, Jafari R, Alikhani MY. Prevalence of ESBL and MBL encoding genes in Acinetobacter baumannii strains isolated from patients of intensive care units (ICU). Saudi journal of biological sciences. 2015;22(4):424-9. [DOI:10.1016/j.sjbs.2015.01.004] [PMID] [PMCID]

13. Vahdani $\mathrm{P}$, Yaghoubi $\mathrm{T}$, Aminzadeh Z. Hospital acquired antibiotic-resistant Acinetobacter baumannii infections in a 400-bed hospital in Tehran, Iran. International journal of preventive medicine. 2011 Jul;2(3):127.

14. Shahcheraghi F, Abbasalipour M, Feizabadi MM, Ebrahimipour GH, Akbari N. Isolation and genetic characterization of metallo- $\beta$-lactamase and carbapenamase producing strains of Acinetobacter baumannii from patients at Tehran hospitals. Iranian journal of microbiology. 2011 Jun;3(2):68.

15. Baran G, Erbay A, Bodur H, Öngürü P, Akıncı E, Balaban N, Çevik MA. Risk factors for nosocomial imipenem-resistant Acinetobacter baumannii infections. International Journal of Infectious Diseases. 2008;12(1):16-21. [DOI:10.1016/j.ijid.2007.03.005] [PMID]

16. Vazirzadeh J, Behshood P, Heidari L, Ghajav $\mathrm{H}$. Frequency of metallo- $\beta$-lactamase and antimicrobial resistance patterns of Acinetobacter baumannii in carbapenem-resistant isolates in intensive care units. Journal of Isfahan Medical School. 2015;32(312):2094103.

17. Aghayan SS, Mogadam HK, Fazli M, DarbanSarokhalil D, Khoramrooz SS, Jabalameli F, Yaslianifard S, Mirzaii M. The effects of berberine and palmatine on efflux pumps inhibition with different gene patterns in Pseudomonas Aeruginosa isolated from burn infections. Avicenna journal of medical biotechnology. 2017 Jan;9(1):2.
18. Musumeci R, Speciale A, Costanzo R, Annino A, Ragusa S, Rapisarda A, Pappalardo MS, Iauk L. Berberis aetnensis C. Presl. extracts: antimicrobial properties and interaction with ciprofloxacin. International journal of antimicrobial agents. $2003 \mathrm{Jul}$ 1;22(1):48-53. [DOI:10.1016/S0924-8579(03)00085-2]

19. Wojtyczka R, Dziedzic A, Kępa M, Kubina R, KabałaDzik A, Mularz T, Idzik D. Berberine enhances the antibacterial activity of selected antibiotics against coagulase-negative Staphylococcus strains in vitro. Molecules. 2014;19(5):6583-96. [DOI:10.3390/molecules19056583] [PMID] [PMCID] 